\title{
Effectiveness study of an online anaphylaxis training program for school personnel: overview of methods for a pilot study in a large Canadian school board
}

\author{
AJ Levinson ${ }^{1}$, L Colizza $^{{ }^{*}}$, L Harada ${ }^{2}$, S Waserman ${ }^{3,4}$, S Garside ${ }^{1}$ \\ From Canadian Society of Allergy and Clinical Immunology Annual Scientific Meeting 2009 \\ Halifax, Canada. 22-25 October 2009
}

\section{Background}

All school personnel in Ontario need to be trained to recognize anaphylaxis, manage an anaphylactic reaction including the administration of an epinephrine autoinjector, and be aware of risk reduction strategies in their school. Training capacity is limited and costly; an online training program offers a potentially efficient, effective and cost-effective model for human resource training.

\section{Objective}

To determine if an online anaphylaxis training program is effective for improving school personnel's knowledge of anaphylaxis and required skills to recognize and respond to an anaphylactic reaction.

\section{Methods}

Setting and Participants: A sample of volunteer personnel using the Toronto District School Board's learning management system representing the key roles/positions employed within the Board. 72 participants will be recruited, comprised of 60 school-based staff (20 secondary school staff, 40 elementary school staff) and 12 administrative staff (e.g. vice-principals). Design: Prospective pretest/immediate post-test/delayed post-test educational research effectiveness study. Intervention: A 45 minute online training program on anaphylaxis, based on the second edition of the handbook, Anaphylaxis in Schools and Other Settings (2005-2009, CSACI) and training materials from Anaphylaxis Canada, and adapted for e-learning using best practices in multimedia training. Primary Outcomes: In addition to self-report of learning satisfaction

${ }^{1}$ Division of e-Learning Innovation, Faculty of Health Sciences, McMaster University, Canada and self-efficacy, knowledge acquisition and retention will be assessed via pretest, immediate post-test, and delayed post-test. Skills to recognize an anaphylactic reaction and administer an epinephrine auto-injector will be assessed by scenario-based questions and tasks. Utilization and completion rates of the program, as well as time on task, will be measured by the Learning Management System. Analysis: Repeated measures ANCOVA will be performed with co-variates of time on task, and pretest score to control for prior knowledge.

\section{Implications}

If effective, online training may become an important strategy for widespread education on anaphylaxis in schools and other environments.

\section{Project partners}

Rita Simmons and Elaine Dimeglio, Toronto District School Board

\section{Study sponsor}

AllerGen NCE Inc.

\section{Author details}

'Division of e-Learning Innovation, Faculty of Health Sciences, McMaster University, Canada. ${ }^{2}$ Anaphylaxis Canada, Canada . ${ }^{3}$ Division of Clinical Immunology \& Allergy, Dept of Medicine, McMaster University, Canada

${ }^{4}$ Canadian Society of Allergy and Clinical Immunology, Canada.

Published: 12 May 2010

\section{doi:10.1186/1710-1492-6-S1-P12}

Cite this article as: Levinson et al:. Effectiveness study of an online anaphylaxis training program for school personnel: overview of

methods for a pilot study in a large Canadian school board. Allergy, Asthma \& Clinical Immunology 2010 6(Suppl 1):P12. 